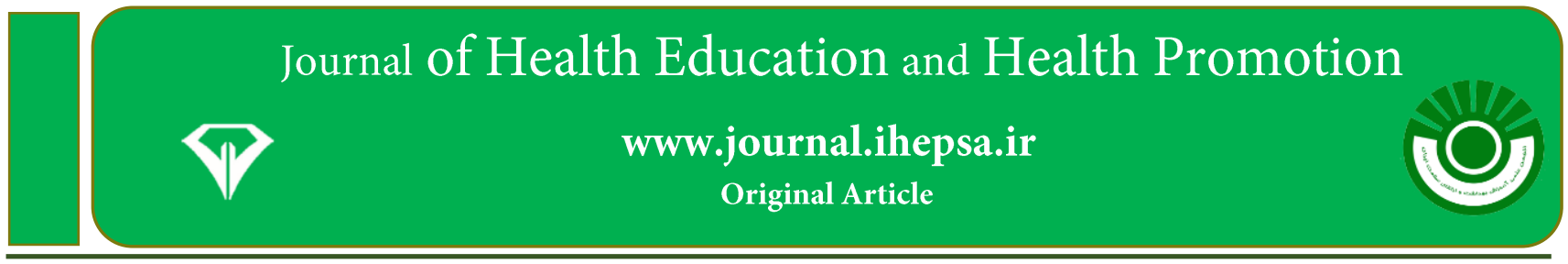

\title{
Effectiveness of Behavioral Activation Treatment on Marital Intimacy and Sexual Satisfaction of Women during Premenopause
}

\author{
Soolmaz Eisanezhad Jahromi, Zahra DashtBozorgi
}

Dept. of Psychology, Faculty of Human Sciences, Ahvaz Branch, Islamic Azad University, Ahvaz, Iran

\section{Article Information}

\section{Article History:}

Received: 2017/09/18

Accepted: 2017/12/25

Available online: 2018/01/30

\section{IJHEHP 2018; 6(1):063-071}

\section{DOI:}

10.30699/acadpub.ijhehp.6.1.63

Corresponding Author:

\section{Zahra DashtBozorgi}

Dept. of Psychology, Faculty of human Sciences, Ahvaz branch, Islamic Azad University, Ahvaz, Iran

\section{Tel: 09163059829}

\section{Email:}

zahradb2000@yahoo.com

Use your device to scan and read the article online

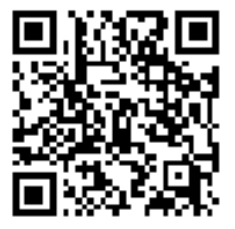

\section{Abstract}

Background and Objective: Among women's main problems during premenopause, difficulty in marital intimacy and sexual satisfaction can be noted. So, present research aimed to investigate the effectiveness of behavioral activation treatment on marital intimacy and sexual satisfaction of women during premenopause.

Methods: This was a quasy-experimental research with a pre-test and post-test designed for experimental and control groups. The statistical population included all women during premenopause of Ahvaz city in 2016. 30 woman were selected by available sampling method and randomly assigned to two equal groups. The experimental group was trained about behavioral activation treatment in 8 sessions of 90 minutes. The groups completed the questionnaires of marital intimacy and sexual satisfaction as a pre-test and post-test. The data were analyzed using Spss-19 software and multivariate analysis of covariance method.

Results: The results showed there was a significant difference between the experimental group and the control group on marital intimacy and sexual satisfaction. In other words behavioral activation treatment significantly led to marital intimacy increasing and sexual satisfaction of women during premenopause $(P<0 / 05)$.

Conclusion: Due to the results, behavioral activation treatment can increase the rate of marital intimacy and sexual satisfaction of women during premenopause, so counselors and therapists can use mentioned treatment method to increase marital intimacy and sexual satisfaction.

KeyWords: Behavioral Activation Treatment, Marital Intimacy, Sexual Satisfaction, Women, Premenopause

Copyright ( 2018 Journal of Health Education and Health Promotion. All rights reserved.

How to cite this article:

Eisanezhad Boshehri S, DashtBozorgi Z. Effectiveness of Behavioral Activation Treatment on Marital Intimacy and Sexual Satisfaction of Women During Premenopause . Iran J Health Educ Health Promot. 2018; 6 (1) : 63-71

Eisanezhad, Boshehri, S., DashtBozorgi, Z.(2018). Effectiveness of Behavioral Activation Treatment on Marital Intimacy and Sexual Satisfaction of Women During Premenopause . Iranian Journal of Health Education and Health Promotion, 6 (1) : 63-71 
اثربخشى درمان فعال سازى رفتارى بر صميميت زناشويى و رضايت جنسى زنان در دوران بيش يائسنى

سولماز عيسىنزاد جهرمى، زهرا دشتبزركى

كَروه روانشناسى، دانشكده علوم انسانى، واحد اهواز، دانشًاه آزاد اسلامى، اهواز، ايران

\begin{tabular}{|c|c|}
\hline جبكيله & اطلاعات مقاله \\
\hline 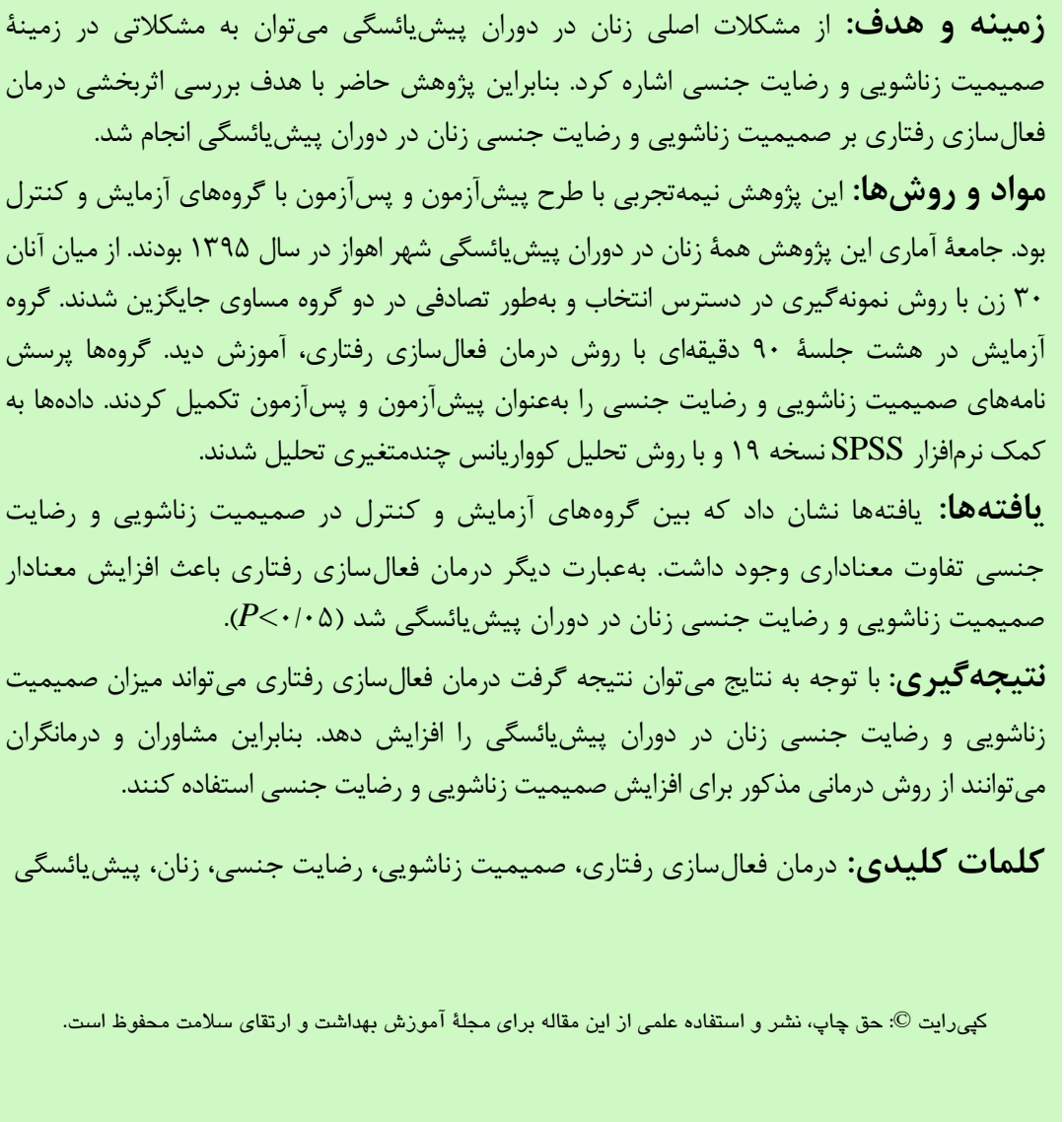 & 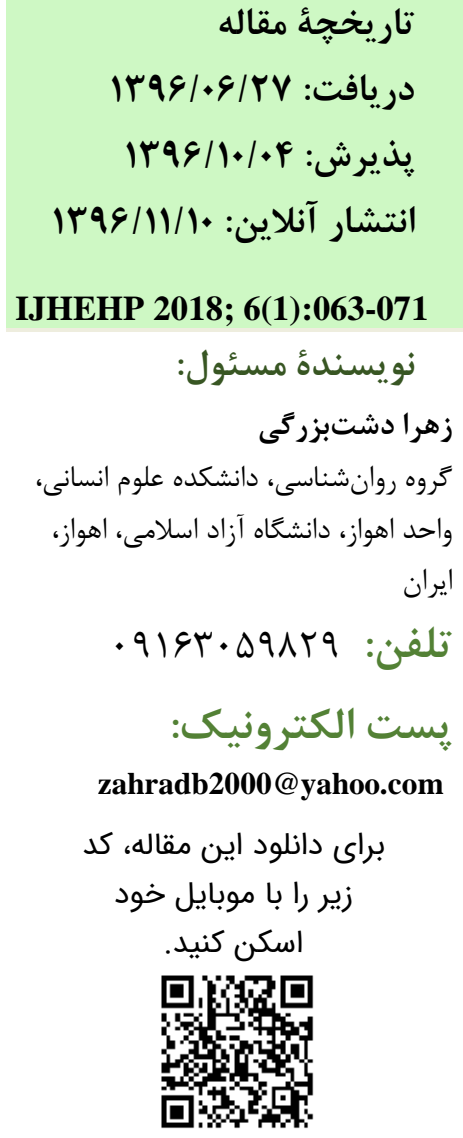 \\
\hline
\end{tabular}

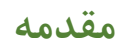

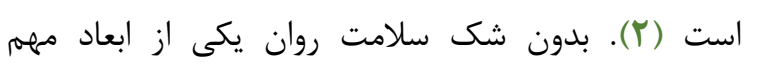

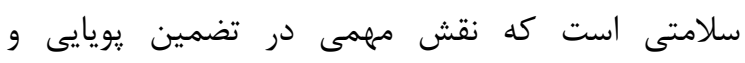

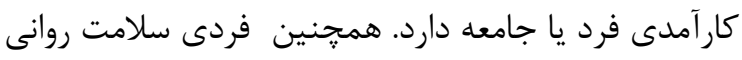

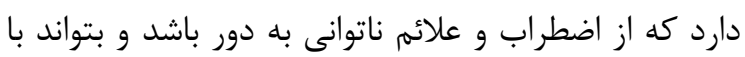

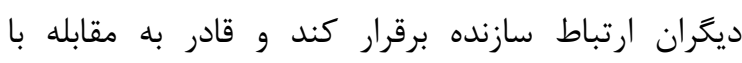

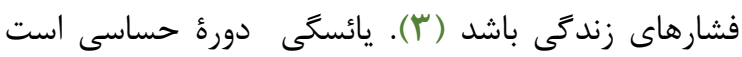

جهبود سلامت روان در هريك از دورانهاى زندكى معلى

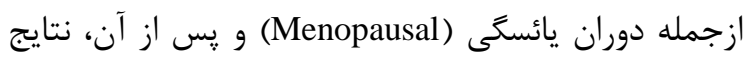

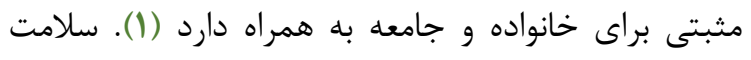

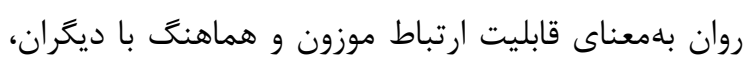

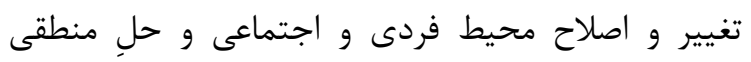

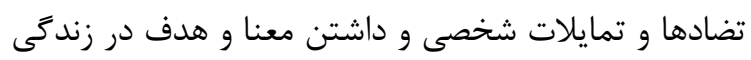


روشهاى درمانى براى بهبود مسائل جنسى در دوران

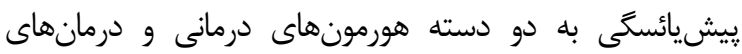
مكمل تقسيم مىشوند (1)). يكى از روشهاى درمانى مكمل، درمان فعالسازى رفتارى (activation treatment Behavioral)

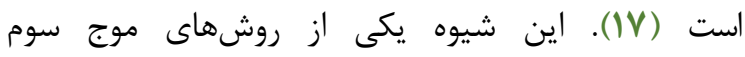

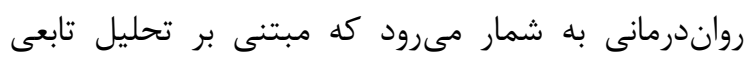
رفتار است (1)). درمان فعالسازى رفتارى براى رسيدن به به بهان

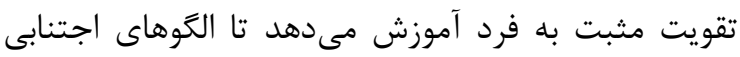

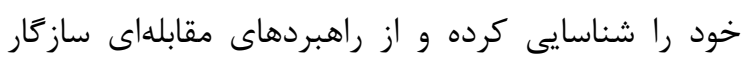

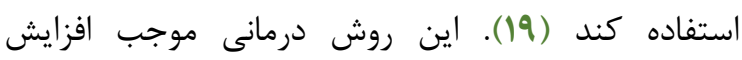

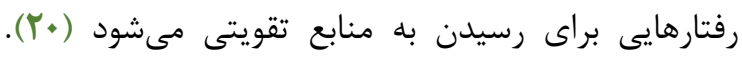

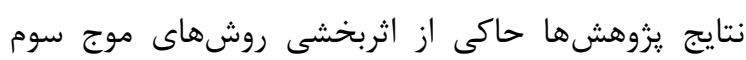

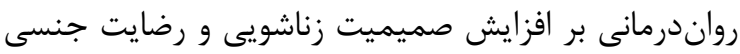

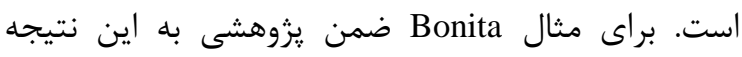
رسيد كه درمان فعالسازى رفتارى باعث كاهش اخت اختلال

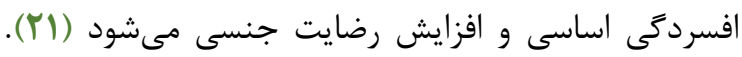

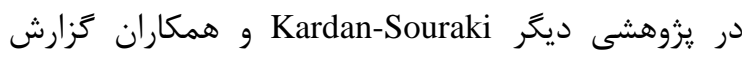

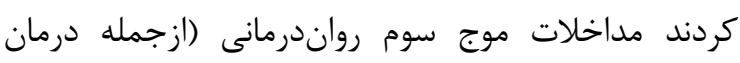

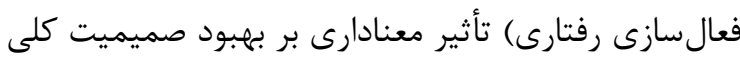

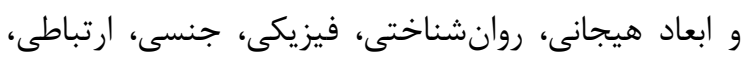

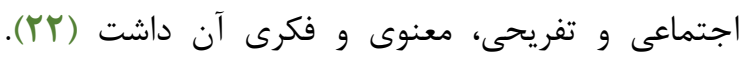

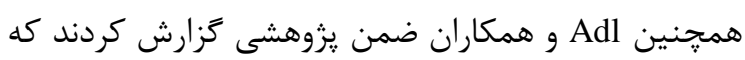

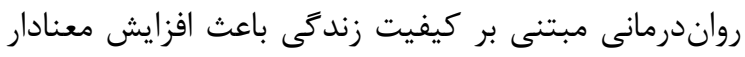

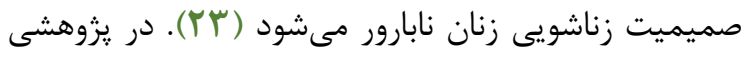
ديكر Mahmudi و همكاران كزارش كردند كه مهارتهائ دمائ

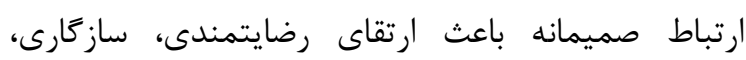

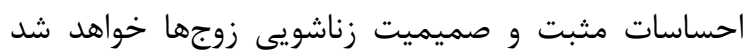

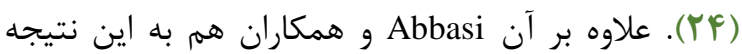

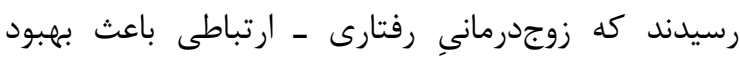

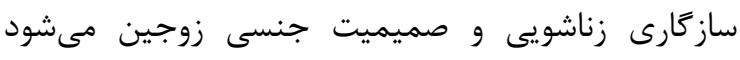

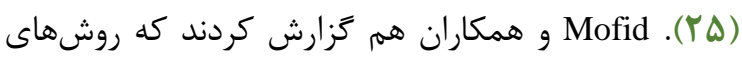

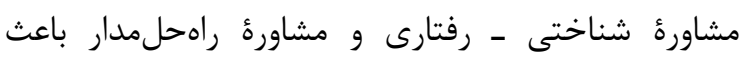

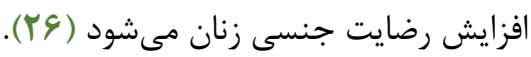

در دوران ييشيائسكى بهسبب تغييرات آناتوميكى،

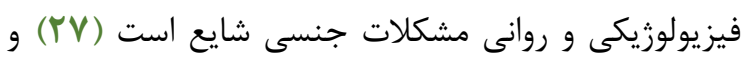

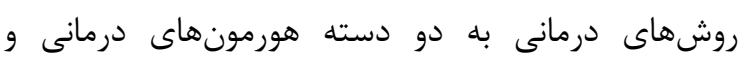

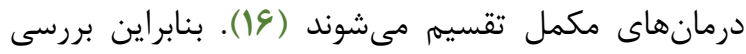
اثربخشى درمانهاى مكمل بر بهببود صميميت زناشويى و ماندي
كه زنان را با مشكلات و دشوارىهاى جديدى روبهرو

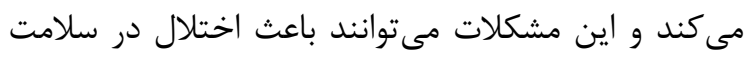

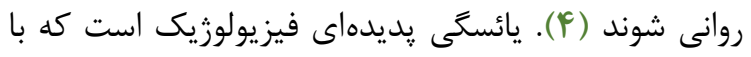

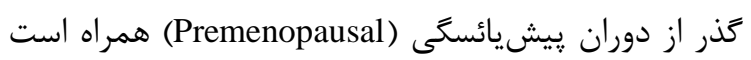

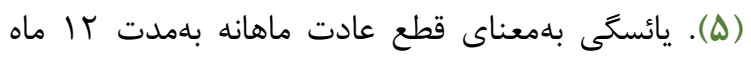

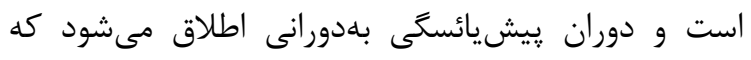

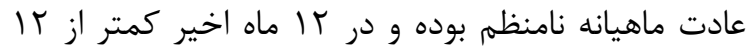

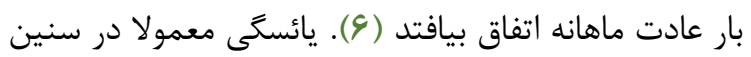

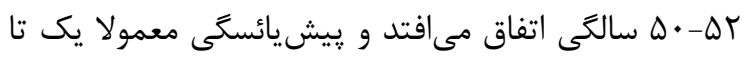

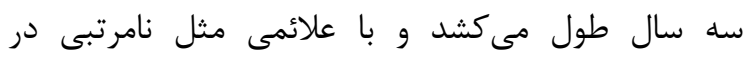

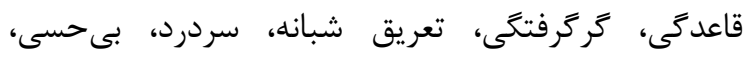

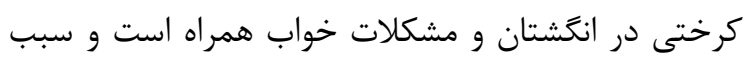

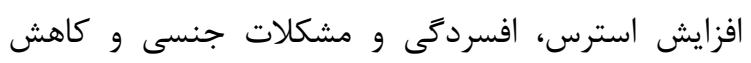

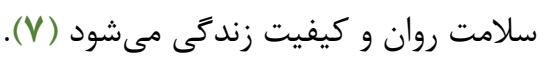
روابط جنسى مطلوب موجب تأمين رضايت طرفين مىشود و نقش بسيار مهمى در رابطهٔ زوجين و استحكام

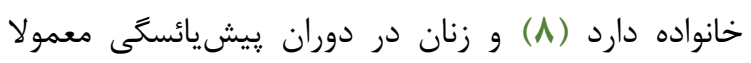
دجار افت صميميت زناشويى (Marital intimacy) مىشوند (V). صميميت بلهنوان نيازى اساسى مستلزم

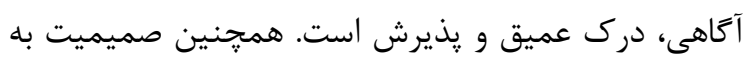

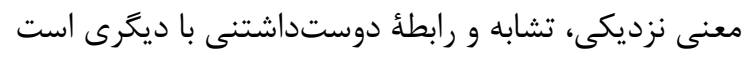

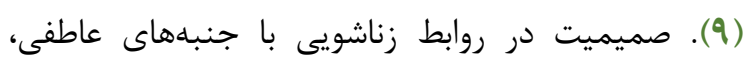

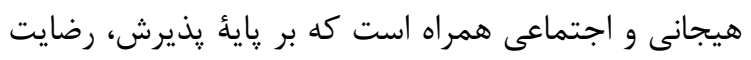

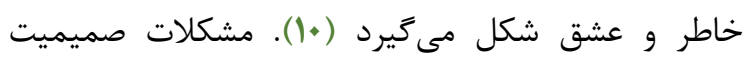

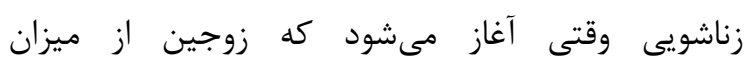

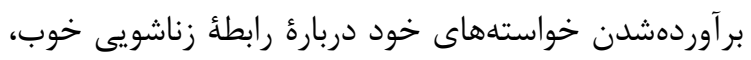

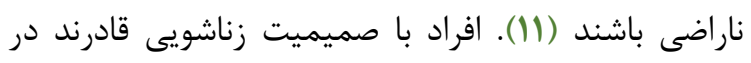
روابط زناشويى خود را به شيؤ مطلوبترى ابراز كنند

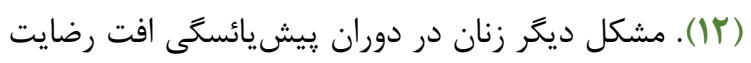

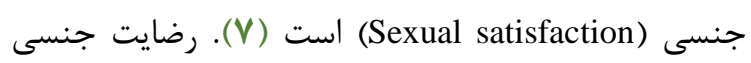

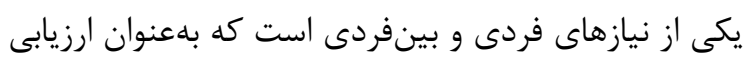

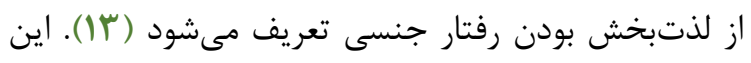
موضوع يكى از عوامل مهم رضايت زناشويى است كه نقش رنش مهمى در سلامت روانى و صميميت زوجين دارد (IF).

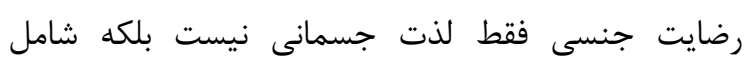

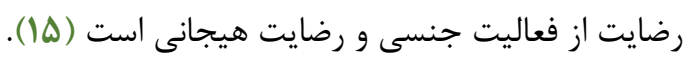


آموزش تخصصى از سوى يك دكتر بالينى كه دوره درمان

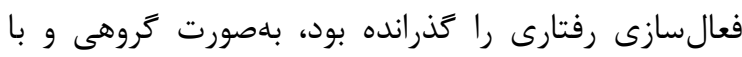

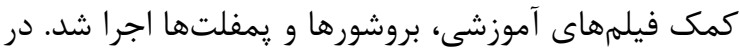

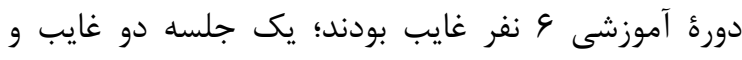

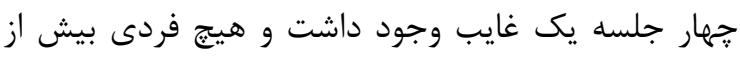
يك جلسه غيبت نداشت. Dimidjain و همكاران محتواى هردي

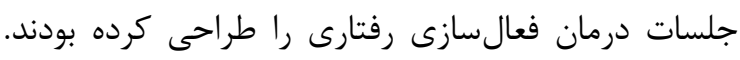

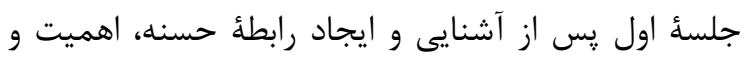

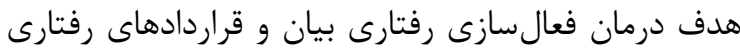
ساده بررسى شدند. جلسؤ دوم فعالسازى رفتار با تمركز بر بر فران

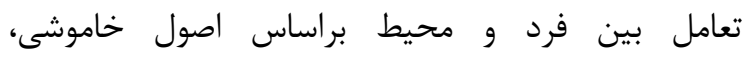

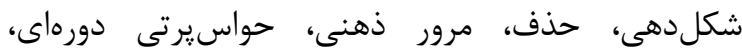
مهارتهاى رويهاى و تفكر نظارهاى آموزش داده شد. جلسهٔ

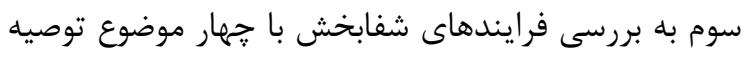
در زمينٔ كلى بيمارى، انتخاب روش درمانى مناسب با بانيا

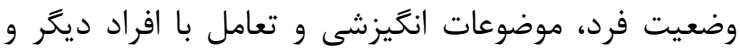

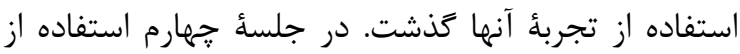

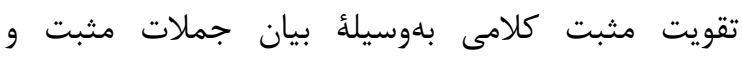
اميدبخش آموخته شد. در جلسة ينجمم درباره استفاده از

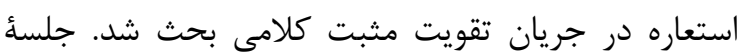

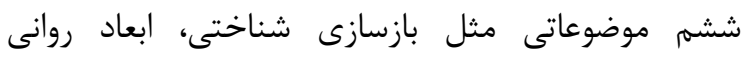

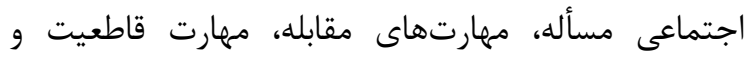

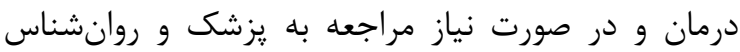

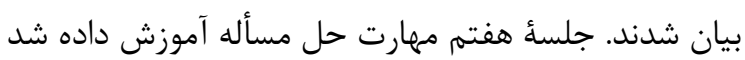

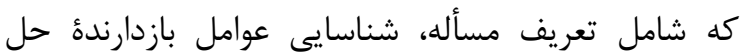
مسأله، فرايند حل مسأله، متعهد شدن براى اجراى راهحل،

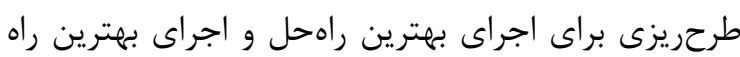

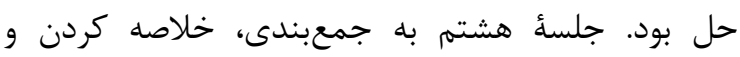
آموزش راهكارهاى بيشخيرانه كذشت. لازم به ذكر است كند در پايان هر جلسه شركت رنندگان تكليفى مبتنى بر

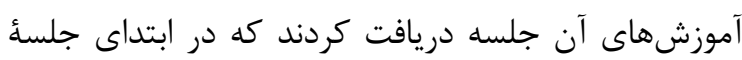

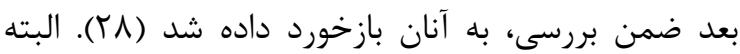

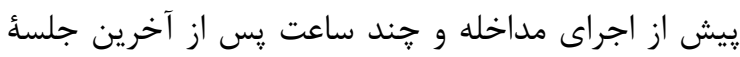

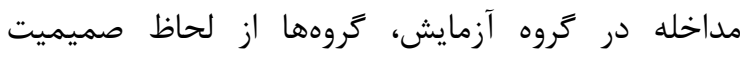
زناشويى و رضايت جنسى با ابزارهاى زير ارزيابى شدرند.

يرسشنامٔ صميميت زناشويى: اين برسشنامه رإن Walker \& Thompson با استفاده از مقياس هفت درجهاى ليكرت (1= هركز تا V= هميشه)
رضايت جنسى ضرورى است. با توجه به اينكه يزوهشهاى

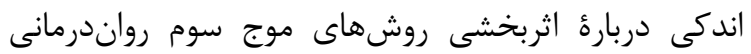
(مثل درمان فعالسازى رفتارى) بر صميميت زناشويى و رضايت جنسى انجام شده و وجود روشهاى مؤثر براى

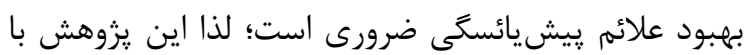

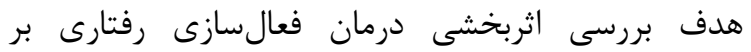
صميميت زناشويى و رضايت جنسى زنان درئ در دران دوران קֵيش يائسكى انجام شد. روش بررسى

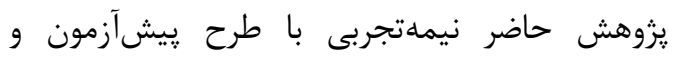
يسآزمون در كروههاى آزمايش و كنترل انجام شد. جامعأ

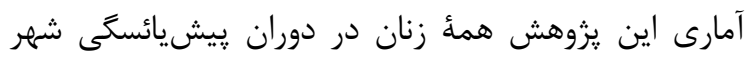

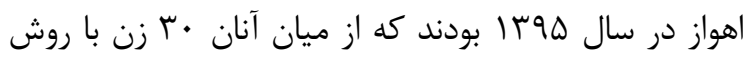
نمونهگيرى در دسترس انتخاب و بلششكل تصادفى در

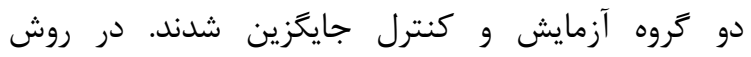

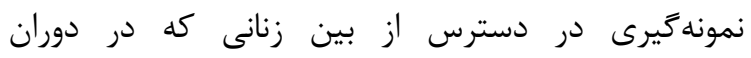

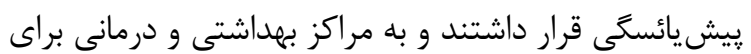

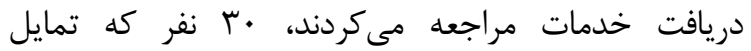

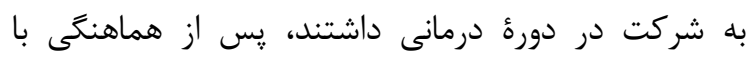

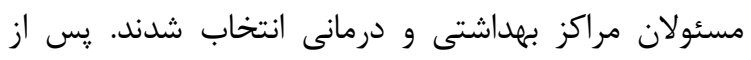

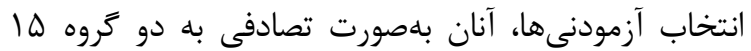
نفرى تقسيم شدند؛ سيس يكى از كروهها تصادفى بلعنوان

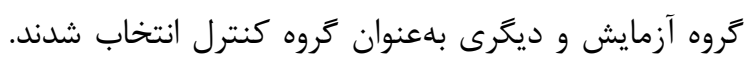

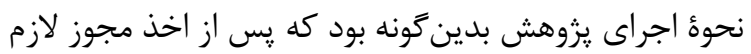

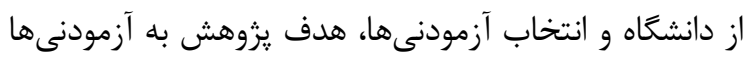

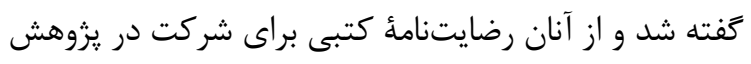

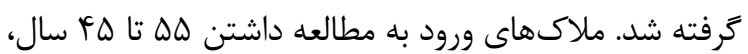
در دوران ييشيائسكى بودن، متأهل بودن، اتفاق نيفتادن وردان رخدادهاى تنشزا مثل طلاق يا مركى عزيزان در 9 ماه باه

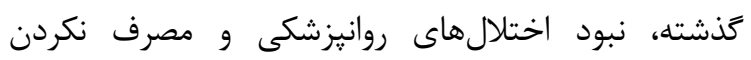

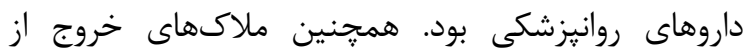

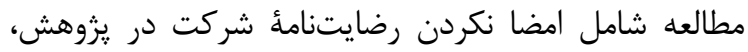

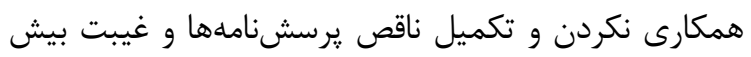

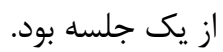

كروه آزمايش بلهمت يك ماه، طى هشت جلسؤ

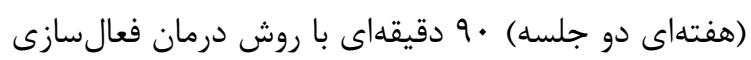

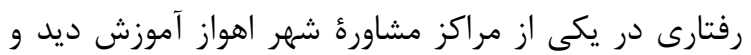

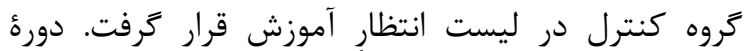




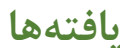

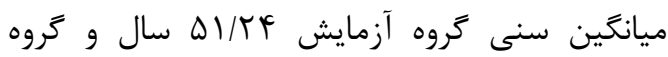

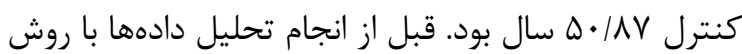

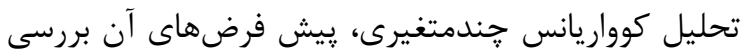

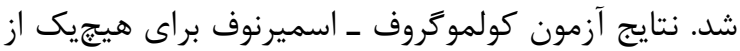

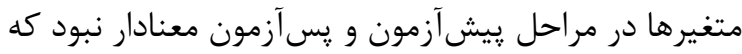
اين يافته حاكى از آن است كه فرض نرمال بودن برقار آندار است. همجنين نتايج آزمون M باكس و آزمون لوين معنادار نبودند. اين يافتهها بهترتيب حاكى از آن آن هستند كه

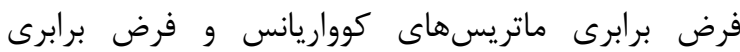
واريانسها برقرار است. بنابراين شرايط استفاده از تحليل

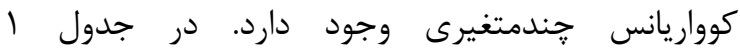
شاخصهاى توصيفى ميانكين و انحراف معيار صميميت

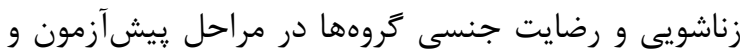
يسآزمون كزارش شد.

طبق نتايج جدول ا در مرحلة يسآزمون ميانگين

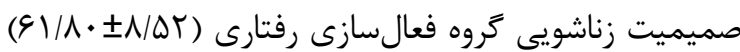
از ${ }^{\prime}$

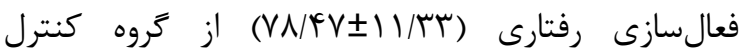
بيشتر است. براى بررسى اثربخشى متغير (FT/TVIV/VI) مستقل بر متغيرهاى وابسته از آزمون جندمتئيرى استفاده براه

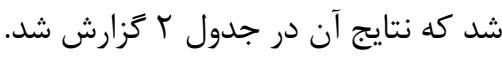

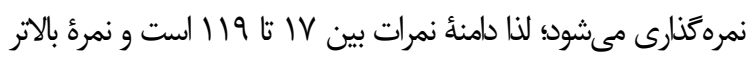

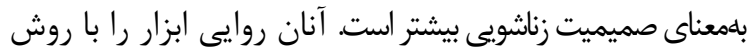

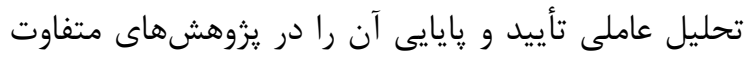

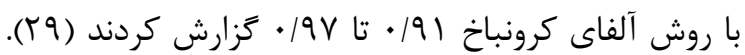
همجنين Kavand يايايى اين ابزار را با روش آلفاى كرونباخ

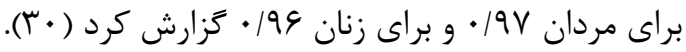

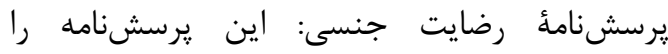
Hudson كه با استفاه از مقياس ينج درجاى ليكرت (1= هركز تا ه= هميشه)

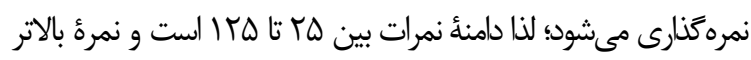

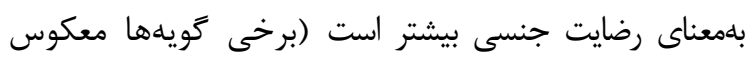

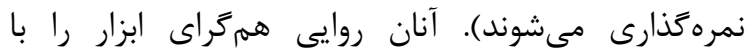

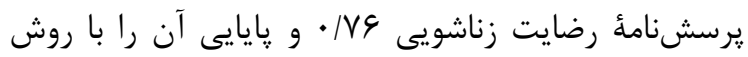

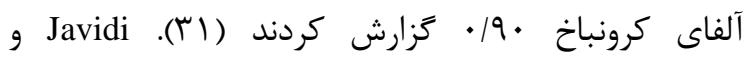
همكاران هم يايايى اين ابزار را با روش آلفاى كروناخ آناخ آناخ

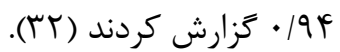

دادهها در دو سطح توصيفى و استنباطى تحليل شدند. در سطح توصيفى از شاخصهاى كرايش مركزى و يراكندگى دوصى براى توصيف توزيع متغيرها و در سطح استنباطى براى

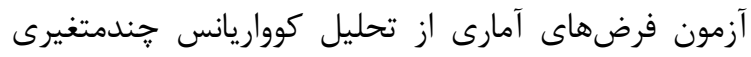

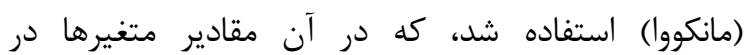

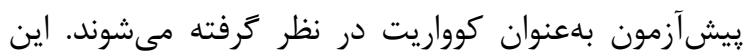

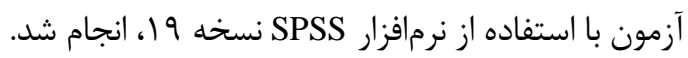

جدول ا. ميانكَين و انحرافمعيار صميميت زناشويى و رضايت جنسى كروهها در مراحل بيشى آزمون و پس آزمون

\begin{tabular}{|c|c|c|c|c|c|c|c|c|}
\hline \multicolumn{4}{|c|}{ رضايت جنسى } & \multicolumn{4}{|c|}{ صميميت زناشويى } & \multirow{3}{*}{ ترو تها } \\
\hline \multicolumn{2}{|c|}{ يسآزمون } & \multicolumn{2}{|c|}{ ي يشآزمون } & \multicolumn{2}{|c|}{ يس آزمون } & \multicolumn{2}{|c|}{ يِيش آزمون } & \\
\hline SD & $\mathrm{M}$ & $\mathrm{SD}$ & $\mathrm{M}$ & $\mathrm{SD}$ & M & $\mathrm{SD}$ & M & \\
\hline (11/r & $V N / F V$ & $V|\Lambda|$ & $r r / T V$ & N/DT & $91 / 1$. & D & $r \Delta / r$. & آزمايش \\
\hline$V / V I$ & FT/TV & $V / 99$ & $F / / \Delta r$ & $\Delta / 4 \mid$ & $r V / T V$ & & $r \varepsilon / q V$ & كنترل \\
\hline
\end{tabular}

جدول ז. نتايج آزمون جندمتغيرى براى بر رسى اثربخشى آموزش بر صميميت زناشويى و رضايت جنسى

\begin{tabular}{|c|c|c|c|c|c|}
\hline مجذور إتا & معنادارى & F آماره F F & مقدار & آزمونها & متغير مستقل \\
\hline$\cdot / 4 \Delta 9$ & $\cdot 1 . .1$ & IT/VGD & - MET & اثر بيلايى & \multirow{4}{*}{ روش فعالسازى } \\
\hline.$|94|$ & $.1 . .1$ & IN/FAT & $.19 \vee \Delta$ & لامبداى ويلكز & \\
\hline - IVTF & $.1 . .1$ & rQ/qTा & $1 / / 49$ & اثر هاتلينَ & \\
\hline . & $.1 . .1$ & VE/TEV & $1 / T \lambda F$ & بزر كترين ريشه روى & \\
\hline
\end{tabular}




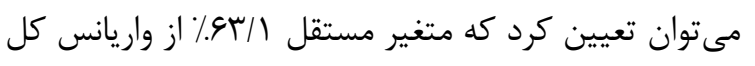
را تبيين مى كند. براى بررسى اثربخشى روش درد درمانى

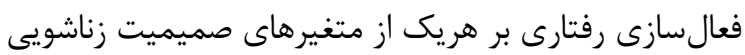

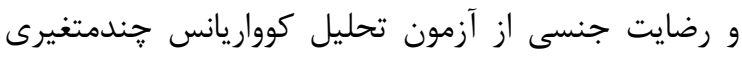

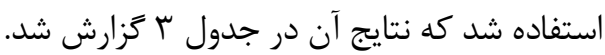

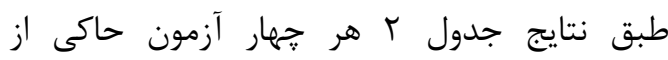
اثربخشى متغير مستقل حداقل بر يكى از متغيرهاى وابسته

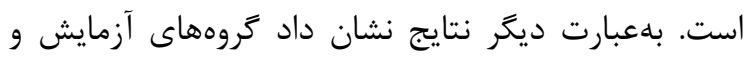
كنترل حداقل در يكى از متغيرهاى صميميت زناشويى و

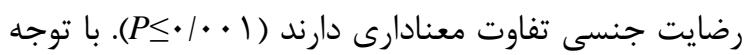
به مقدار مجذور اتاى آزمون لامبداى ويلكز (اسباءل)

جدول ب. نتايج تحليل كوواريانس جندمتغيرى گروهها در متغيرهاى صميميت زناشويى و رضايت جنسى

\begin{tabular}{|c|c|c|c|c|c|c|c|}
\hline مجذور إتا & معنادارى & آماره F & مجذانكين & درجة آزادى & مجذوروات & منبع اثر & متغيرهاى وابسته \\
\hline$\cdot|4| 1$ & $.1 \cdot 1$ & rQ/VFT & $9 \% / 9 \vee 9$ & 1 & $9 Y / 9 \vee 9$ & يِيش آزمون & \multirow{4}{*}{ صميميت زناشويى } \\
\hline \multirow[t]{3}{*}{$.19 V T$} & $.1 . .1$ & DT/TTV & $\mid \varepsilon r / r 9 \Delta$ & 1 & $18 r / r 9 \Delta$ & تروه & \\
\hline & & & r/Tre & rV & $\Lambda F / F \cdot T$ & واريانس خطا & \\
\hline & & & & $r$. & |QRq/·Ar & واريانس كل & \\
\hline.$/ 499$ & $.1 . .1$ & Tr/TTS & $|r F / q T|$ & 1 & $|K F / Q Y|$ & يِيش آزمون & \multirow{4}{*}{ رضايت جنسى } \\
\hline \multirow[t]{3}{*}{$\cdot / V \Delta \Lambda$} & $\cdot 1 \cdot .1$ & $\Delta \Lambda / N T I$ & $r / 9 / r T \Lambda$ & 1 & r/9/rTA & كروه & \\
\hline & & & r/VG. & TV & $1 \cdot 1 / \Delta T \cdot$ & واريانس خطا & \\
\hline & & & & $r \cdot$ & $1 \wedge r F / 9 \Delta G$ & واريانس كل & \\
\hline
\end{tabular}

(از جمله درمان فعالسازى رفتارى) تأثير معنادارى بر بهبود صميميت كلى و ابعاد صميميت مثل هيجانى، روان شناختى، فيزيكى، جنسى، ارتباطى، اجتماعى و تفريحى،

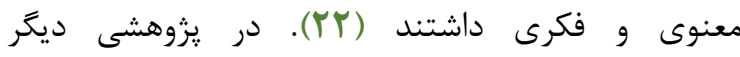
Mahmudi

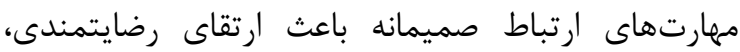
ساز Fارى، احساسات مثبت و صميميت زناشويى زوجها شد ارداط

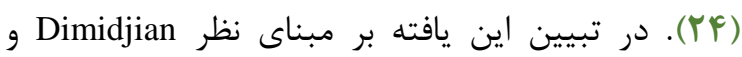
همكاران (YA) مى (Y) اين دليل اثربخش است كه منجر به افزايش تقويت مثبت

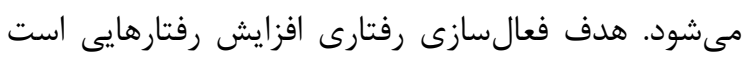
كه احتمالا منجر به دريافت ياداش از سوى بيمار مىشوند رئد

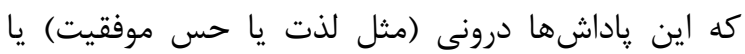
بيرونى (مثل توجه اجتماعى) هستند. اين افزايش پاداشها

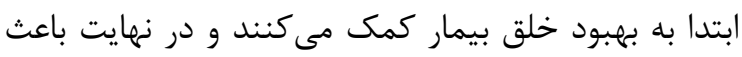

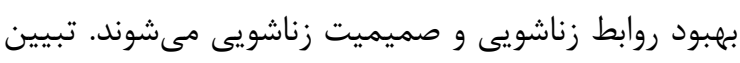
ديخر بر مبناى نظر Kanter و همكاران (سM) اين است كه درمان فعال سازى رفتارى به افراد آموزش مىدهد تا سبك مبك زندگى خود را عوض كنند و قانونهاى جديدى رئ را در زندگى خود وضع و آنها را دنبال كنند. مثلا افراد ياد مى گيرند هنگام احساس غم بهجاى خاموش بودن فعالتر شوند، اقدام به حل مشكل كرده و يا از ديخران (همسر)
طبق نتايج جدول س درمان فعالسازى رفتارى تأثير معنادارى بر نمرات پيسآزمون داشت كه با درنظرگرفتن

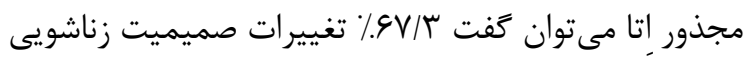

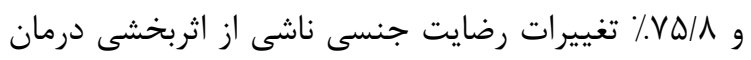

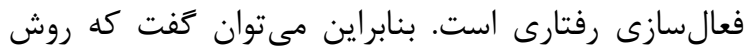
درمان فعالسازى رفتارى باعث افزايش معنادار صميميت

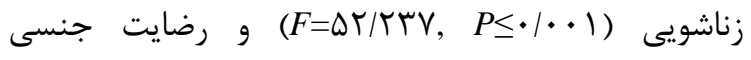

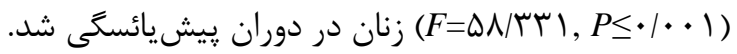

\section{بִ}

اين يزوهش با هدف بررسى اثر درمان فعالسازى رفتارى بر صميميت زناشويى و رضايت جنسى زنان در

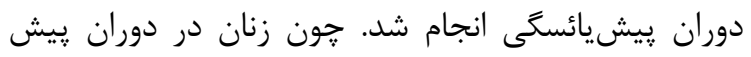

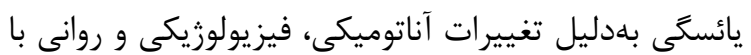
مشكلات فراوانى بلويزه در زمينه روابط زناشويى مواجه

هستند.

يافتهها نشان داد درمان فعالسازى رفتارى باعث افزايش صميميت زناشويى شد كه اين يافته با يافتهٔ يزوهشهاى Kardan-Souraki و همكاران (Yr)، Adl و همكاران (YMahmudi و و همكاران (YY) همrسو بود. براى مثال Kardan-Souraki و همكاران ضمن يزوهشى به وان وان اين نتيجه رسيدند كه مداخلات موج سوم رواندرمانى 
غيره) و در نهايت باعث افزايش ادراك مثبت افراد از روابط

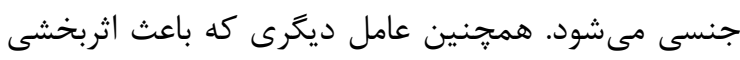

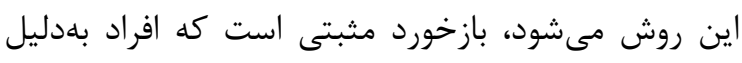

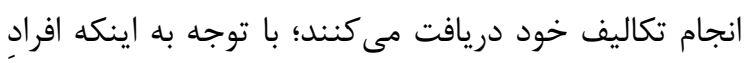
با مشكلات خاص (مثل زنان در دوران زيشيش ديائسكى)

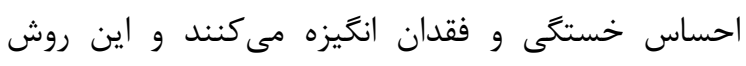
درمانى باعث بيشتر انرزى داشتن و مثبت فيتانديشى آنيز آنها

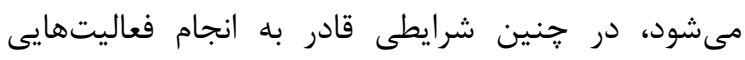

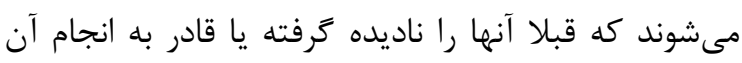

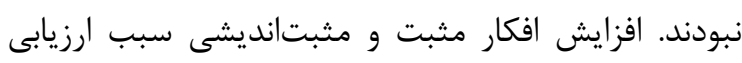

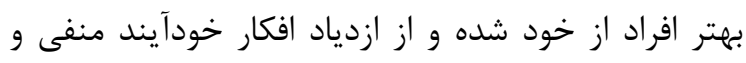

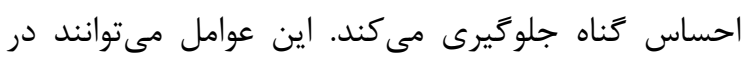

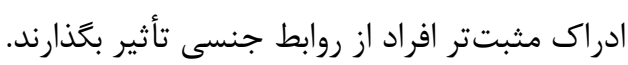

نخستين محدوديت يزوهش حاضر استفاده نكردن از

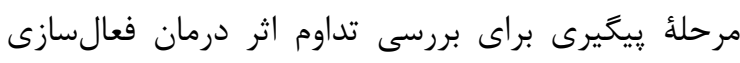

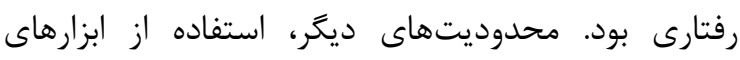

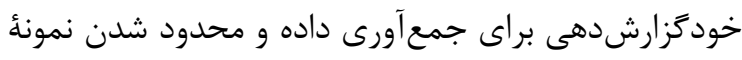

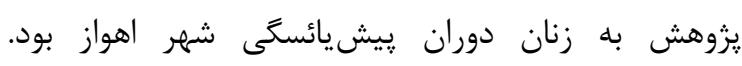

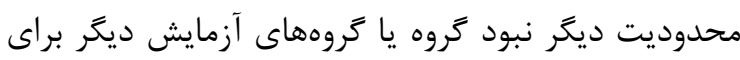

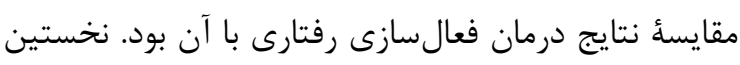

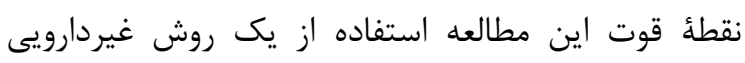

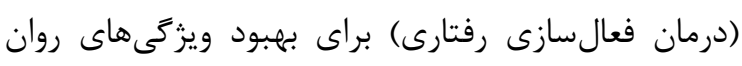

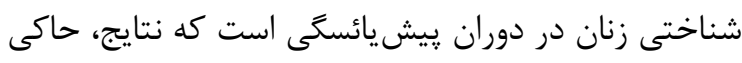

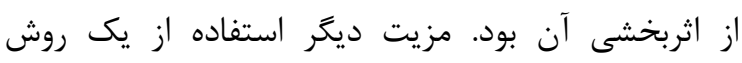

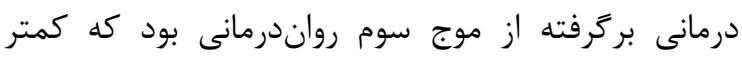

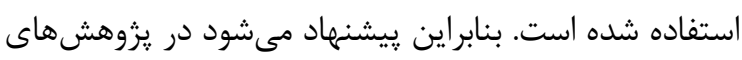

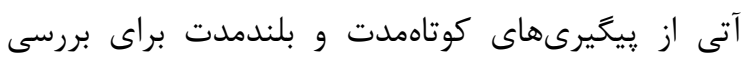

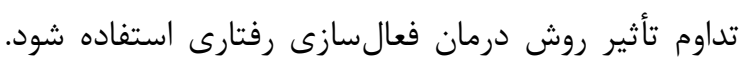

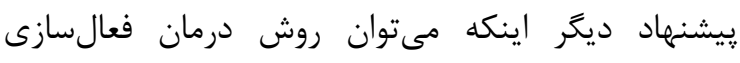

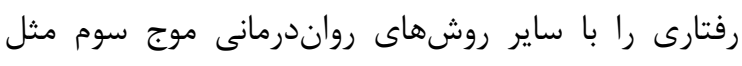

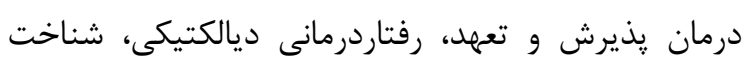

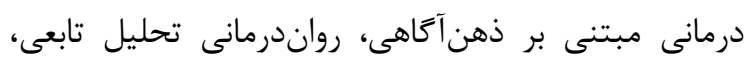

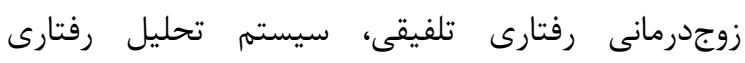

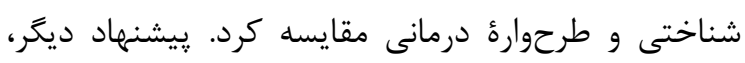

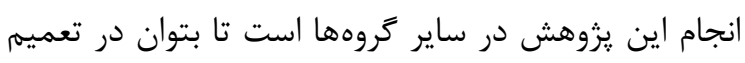

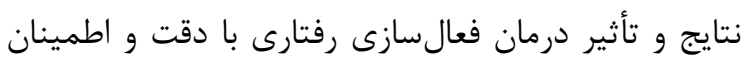
بيشترى بحث كرد.
درخواست كمك كنند. همجنين اين شيوه، راهبرد

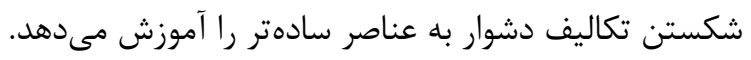

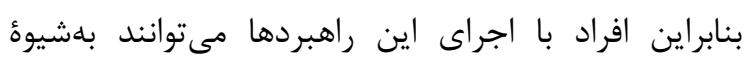

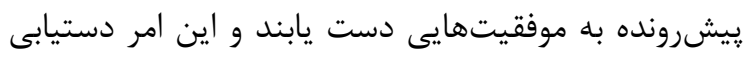

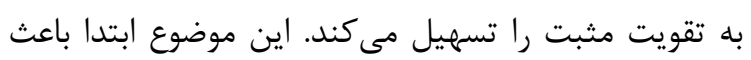

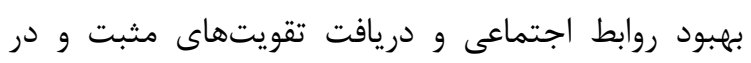
نهايت باعث بهبود صميميت زناشويى مىشود وردي

همجنين يافتهها نشان داد درمان فعالسازى رفتارى باعث افزايش صميميت زناشويى شد كه اين يافته با يافتهأ

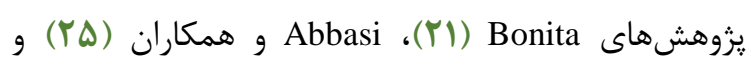
Mofid

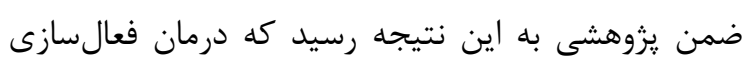

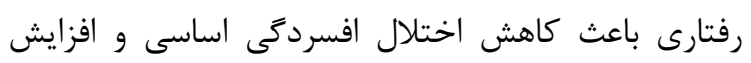

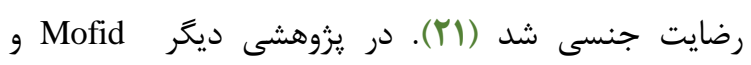

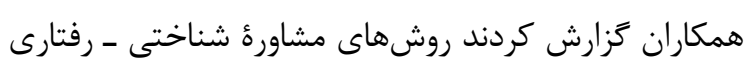

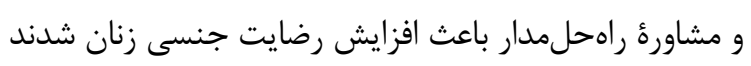

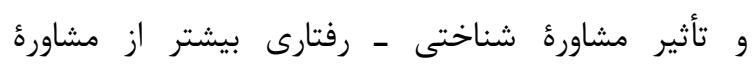

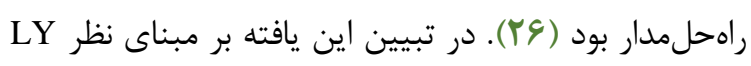

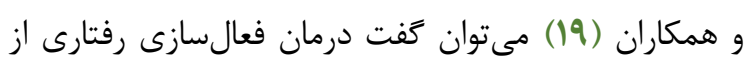
راهبرد شكستن تكاليف دشوار به تكاليف و عناصر سادهتر

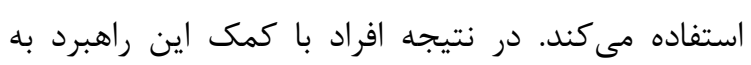

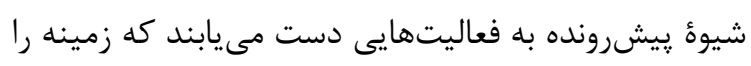

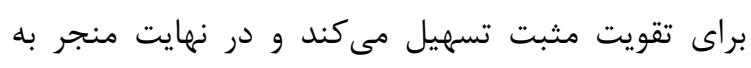

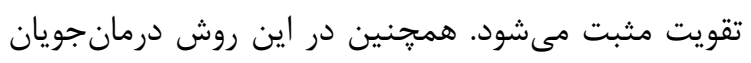

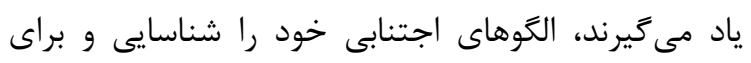

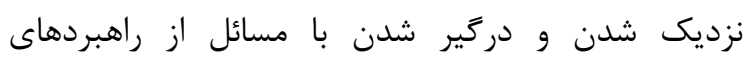

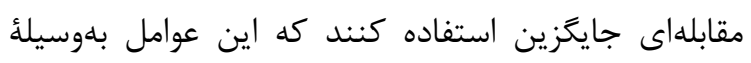

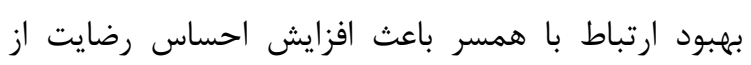

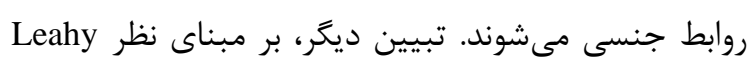

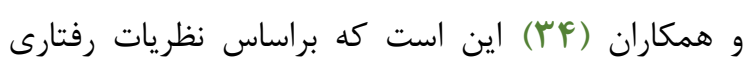

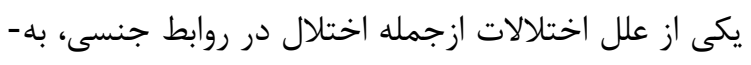

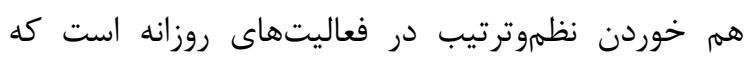

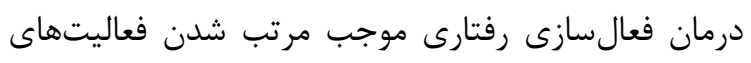

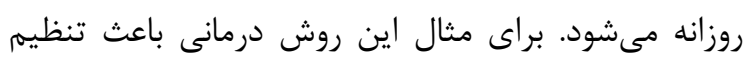

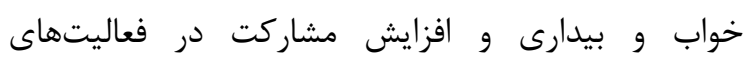

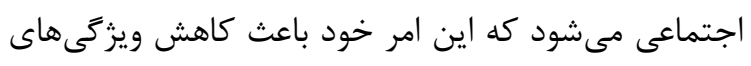

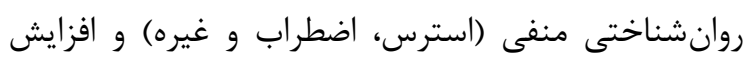

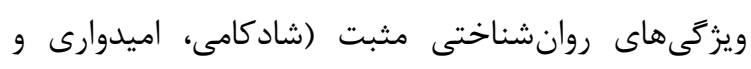




$$
\begin{aligned}
& \text { صميميت زناشويى و رضايت جنسى استفاده كنند. }
\end{aligned}
$$

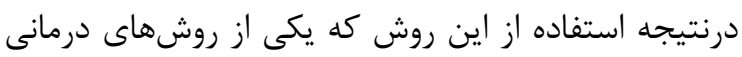

$$
\begin{aligned}
& \text { مكمل است، براى زنان در دوران پِيشيائسگى توصيه } \\
& \text { مى شود. } \\
& \text { سباسَز;ارى } \\
& \text { اين مقاله با كد مصوب لناس } \\
& \text { يايان نامة كارشناسى ارشد روانشناسى عمومى دانشخاه آزاد }
\end{aligned}
$$

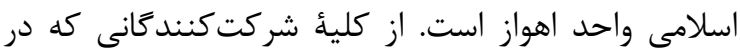

$$
\begin{aligned}
& \text { انجام اين يزوهش كمك كردند، تشكر و قدردانى مىشود. } \\
& \text { لازمبهذكر است كه هيج تعارض منافعى بين نويسند }
\end{aligned}
$$

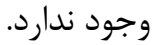

$$
\begin{aligned}
& \text { تعارض در منافع } \\
& \text { بين نويسندكان هيجَّونه تعارضى در منافع كزارش }
\end{aligned}
$$$$
\text { نشده است. }
$$

\section{References}

1. Seib C, Anderson D, Lee K, Humphreys J. Predictors of mental health in post-menopausal women: Results from the Australian healthy aging of women study. Maturitas. 2013;76(4):377-83. https://doi.org/10.1016/j.maturitas.2013.09.003 PMid:24200224

2. Liu H, Li F, Li J, Zhang Y. The relationships between urban parks, residents' physical activity, and mental health benefits: A case study from Beijing, China. J Envir Manage. 2017;190(4):223-30. https://doi.org/10.1016/j.jenvman.2016.12.058 PMid:2 8056355

3. Zonderman AB, Ejiogu N, Norbeck J, Evans MK The influence of health disparities on targeting cancer prevention efforts. Am J Prev Med. 2014;46(3):S87-S97. https://doi.org/10.1016/j.amepre.2013.10.026 PMC4431696

4. Seydi Z. Relationship between mental health and quality of life in menopause women in Sity Ilam in 2014 Year. J Health Breeze. 2015;3(2):44-50.

5. Oakley SH, Walther-Liu J, Crisp CC, Pauls RN. Acupuncture in premenopausal women with hypoactive sexual desire disorder: a prospective cohort pilot study. Sex Med. 2016;4(3):176-81. https://doi.org/10.1016/j.esxm.2016.02.005 PMC5005297

6. Mohammad-Alizadeh-Charandabi S, Mirghafourvand M, Aghamiri V, Nazemiyeh H, Soltanpoor S. Efficacy of hop (Humuluslupulus L.) on early menopausal symptoms in premenopausal women: a randomized double blind placebo-controlled trial. Sci J Kurdistan Univ Med Sci. 2014;19(3):12-22.

$$
\begin{aligned}
& \text { نتيجنه كيرى } \\
& \text { روشهاى درمانى براى بهبود مسائل جنسى در دوران }
\end{aligned}
$$

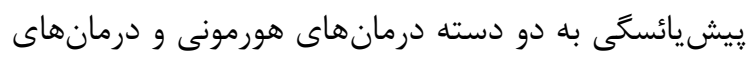

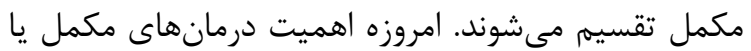

$$
\begin{aligned}
& \text { غيردارويى در مقايسه با كذشته بسيار برجستهتر شده و }
\end{aligned}
$$

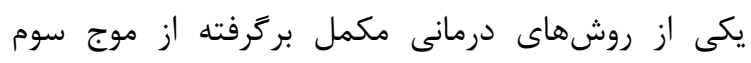

$$
\begin{aligned}
& \text { رواندرمانى، روش درمان فعالسازى رفتارى است. نتايج } \\
& \text { اين يزوهش نشان داد كه درمان فعالسازى رفتارى باعث }
\end{aligned}
$$

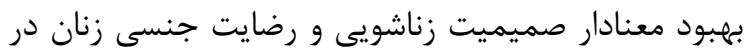

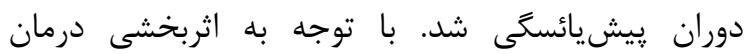

$$
\begin{aligned}
& \text { فعالسازى رفتارى، اين روش قابليت كاربرد در مراكز }
\end{aligned}
$$

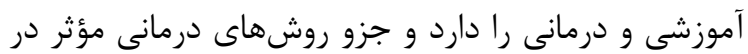

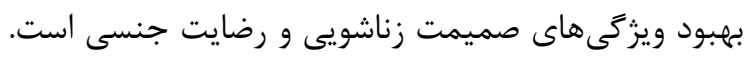

$$
\begin{aligned}
& \text { بنابراين مشاوران، روانشناسان بالينى و و درمانغران }
\end{aligned}
$$

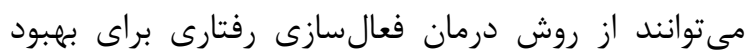

7. Pae C, Mandelli L, Kim T, Han C, Masand PS, et al. Effectiveness of antidepressant treatments in premenopausal versus post-menopausal women: A pilot study on differential effects of sex hormones on antidepressant effects. Biomed Pharmacother. 2009;63(3):228

https://doi.org/10.1016/j.biopha.2008.03.010 PMid:18502089

8. Samaeilvand N, Hasanvand B. The relationship between sexual knowledge and marital forgiveness with mental health of married women. Iran J Health Educ Health Promot. 2015;2(4):270-80.

9. Yoo H, Bartle-Haring S, Day RD, Gangamma R. Couple communication, emotional and sexual intimacy, and relationship satisfaction. J Sex Marital Ther. 2014;40(4):275-93. https://doi.org/10.1080/0092623X.2012.751072 PMid:24111536

10. Zerach G, Anat B, Solomon Z, Heruti R. Posttraumatic symptoms, marital intimacy, dyadic adjustment, and sexual satisfaction among exprisoners of war. J Sex Med. 2010;7(8):2739-49. https://doi.org/10.1111/ j.17436109.2010.01784.x PMid:20367776

11. Canavarro MC, Silva S, Moreira H. Is the link between posttraumatic growth and anxious symptoms mediated by marital intimacy in breast cancer patients? Eur J Oncol Nurs. 2015;19(6):673-9. https://doi.org/10.1016 /j.ejon.2015.04.007 PMid:26009312

12. Jun E, Kim S, Chang S, Oh K, Kang HS, Kang SS. The effect of a sexual life reframing program on marital intimacy, body image and sexual function among breast cancer survivors. Cancer Nurs. 
2011;34(2):142-9.

https://doi.org/10.1097/NCC.0b013e3181f1ab7a PMid:20885305

13. Flynn KE, Lin L, Bruner DW, Cyranowski JM, Hahn EA, et al. Sexual satisfaction and the importance of sexual health to quality of life throughout the life course of U.S. adults. J Sex Med. 2016;13(11):164250. $\quad$ https://doi.org/10.1016/j.jsxm.2016.08.011 PMC5075511

14. Seftel AD. Female partners of men with peyronie's disease have impaired sexual function, satisfaction, and mood, while degree of sexual interference is associated with worse outcomes. J Urolo. 2016;196(5):1516-7. https://doi.org/10.1016/j.juro.2016.08.062

15. Chan JL, Letourneau J, Salem W, Cil AP, Chan S, et al. Sexual satisfaction and quality of life in survivors of localized cervical and ovarian cancers following fertility-sparing surgery. Gynecol Oncol. 2015;139(1):141-7.

https://doi.org/10.1016/j.ygyno.2015.07.105 PMid: 26232519

16. Taavoni S, Nazem Ekbatani N, Haghani H. Effect of afrodit on sexual satisfaction in menopausal women. Arak Med Univ J. 2014;17(84):10-18.

17. Chu BC, Crocco ST, Esseling P, Areizaga MJ, Lindner AM, Skriner LC. Transdiagnostic group behavioral activation and exposure therapy for youth anxiety and depression: Initial randomized controlled trial. Behav Res Thera. 2016;76(1):65-75. https://doi.org/10.1016/j.brat.2015.11.005 PMid:26655958

18. Moshier SJ, Otto MW. Behavioral activation treatment for major depression: a randomized trial of the efficacy of augmentation with cognitive control training. J Affec Disor. 2017;210:265-8. https:// doi.org/10.1016/i.jad.2017.01.003 PMid:28068613

19. Ly KH, Janni E, Wrede R, Sede M, Donker T, et al. Experiences of a guided smartphone-based behavioral activation therapy for depression: A qualitative study. Internet Interv. 2015;2(1):60-8. https://doi.org/ 10.1016/j.invent.2014.12.002

20. Chartier JS, Provencher MD. Behavioral activation for depression: efficacy, effectiveness and dissemination. J Affec Disor. 2013;145(3):292-9. https://doi.org/10.1016/j.jad.2012.07.023 PMid:22884236

21. Bonita AG. Computerized behavioral activation treatment for major depressive disorder and the effects on sexual desire. [PhD Thesis]. Western Michigan University; 2013.

22. Kardan-Souraki M, Hamzehgardeshi Z, Asadpour I, Mohammadpour RA, khani S. A review of marital intimacy-enhancing interventions among married individuals. Glob J Health Sci. 2016;8(8):74-93. https://doi.org/ 10.5539/gjhs.v8n8p74 PMC5016345

23. Adl H A, Shafi Abadi A, Pirani Z. The effectiveness of group therapy based on quality of life on marital intimacy in infertile women. Arak Med Univ J. 2017;19(10):59-71.
24. Mahmudi M, Zahrakar K, Amirian A, Davarniya R, Babaei Gharmkhani M. The effect of group training of practical application of intimate relationship skills (PAIRS) program on enhancine marital satisfaction, adjustment, positive feelings and intimacy of couples. J Urmia Nurs Midwifery Fac. 2016;13(10):869-81.

25. Abbasi M, Bagiyan M, Dargahi S, Ghamari Givi H. Effectiveness of behavioral-communication couple therapy on marital adjustment and sexual intimacy. Iran J Nurs. 2015;28(95):22-33.

26. Mofid V, Ahmadi A, Etemadi O. The comparison of cognitive-behavioral counseling and solutionoriented counseling on women's sexual satisfaction in Isfahan. J Woman Soc. 2014;5(3):67-83.

27. Merki-Feld GS, Imthurn B, Rosselli M, Spanaus K. Serum concentrations of high-molecular weight adiponectin and their association with sex steroids in premenopausal women. Metabol. 2011;60(2):180-5. https://doi.org/10.1016/j.metabol.2009.12.010 PMid:20096895

28. Dimidjian S, Martell CR, Addis ME, Herman-Dunn R. Behavioral activation for depression. In Barlow $\mathrm{DH}$, editor. Clinical handbook of psychological disorders, 4th ed. A step-by-step treatment manual. New York: Guilford Press; 2008. PMC2648513

29. Mitchell AE, Castellani AM, Herrington RL, Joseph JI, Doss BD, Snyder DK. Predictors of intimacy in couples' discussions of relationship injuries: An observational study. J Fam Psychol. 2008;22 (1):21. https://doi.org/10.1037/0893-3200.22.1.21 PMid:18266529

30. Kavand M. Investigation the relationship between selfness behavior, selfness motivation and perception of fairness with marital intimacy in parents of elementary school students in Brojerd city. [MA Thesis]. Ahvaz: Shahid Chamran University; 2011.

31. Rosen NO, Bergeron S, Leclerc B, Lambert B, Steben M. Woman and partner-perceived partner responses predict pain and sexual satisfaction in provoked Vestibulodynia (PVD) couples. J Sex Med. 2010;7(11):3715-24. https://doi.org/10.1111/j.17436109.2010.01957.x PMid:20701677

32. Javidi N, Soleimani AA, Ahmady KH, Samadzadeh M. The Eefectiveness of training of emotion management strategies according to emotionally focused couple therapy (EFT) to increase sexual satisfaction in couples. J Health Psychol. 2012; 1(3):5-18.

33. Kanter J, Santiago-Rivera A, Santos M, Nagy G, Lopez M, Hurtado G, et al. A Randomized hybrid efficacy and effectiveness trial of behavioral activation for Latinos with depression. Behav Ther. 2015;46(2):177-92. https://doi.org/10.1016/j.beth.2014.09.011 PMid:25645167

34. Leahy RL, Holland SJ, McGinn LK. Treatment plans and interventions for depression and anxiety disorders. 2nd ed. New York: Guilford Press; 2012. 